\title{
Perception of Exercise-Induced Bronchoconstriction in College Athletes
}

\author{
David M Burnett PhD RRT AE-C, John P Vardiman PhD ATC, Jake A Deckert MSc, \\ Jaimie L Ward and Matthew R Sharpe MD
}

\begin{abstract}
BACKGROUND: Exercise-induced bronchoconstriction (EIB) can lead to long-term respiratory illness and even death. EIB prevalence rates are both high and variable in college athletes. Also, prevalence rates may be underestimated due to ineffective screening. The purpose of this study is to investigate the prevalence of EIB and the perceived impact of EIB in college athletes via a self-report questionnaire. METHODS: A self-report EIB questionnaire was administered to college athletes on 8 different sports teams. Information collected was used to identify athletes who selfreported: (1) a history of EIB and/or asthma, (2) respiratory symptoms during exercise, (3) medication use, and (4) concern about EIB. RESULTS: Results showed that 56 of 196 athletes (28.6\%) self-reported a history of EIB or asthma. Over half $(52 \%)$ reported a history of EIB/asthma or current EIB symptoms. Forty-six of the 140 athletes $(32.9 \%)$ who did not report a history of EIB or asthma indicated symptoms of EIB during sports, training, or exercise. Fourteen of 56 athletes (25\%) self-reporting a history of EIB or asthma did not report the use of a respiratory medication. Nineteen of 196 athletes $(9.7 \%)$ reported being concerned that EIB was adversely affecting their sports performance. CONCLUSIONS: College athletes self-report a high prevalence of EIB or asthma. Although college athletes may not report a history of EIB or asthma, they indicate symptoms of EIB. A majority of athletes reported a history or current symptoms related to EIB or asthma. Many athletes with a history of EIB or asthma are not taking any asthma medication. Last, athletes report concern about EIB adversely affecting their sports performance. More work is needed using a combination of a screening questionnaire and standardized EIB testing to develop a validated tool for accurately screening and diagnosing EIB in college athletes. Key words: bronchoconstriction; respiratory; asthma; exercise; sports; athletes. [Respir Care 2016;61(7):897-901. (C 2016 Daedalus Enterprises]
\end{abstract}

\section{Introduction}

Exercise-induced bronchoconstriction (EIB) can cause intermittent inflammation and constriction of the airways, characterized by symptoms of chest tightness, wheezing,

Drs Burnett and Sharpe are affiliated with the University of Kansas Medical Center, Kansas City, Kansas. Dr Vardiman, Mr Deckert, and Mr Ward are affiliated with the University of Kansas, Lawrence, Kansas.

Dr Burnett presented a version of this paper as an Editors' Choice abstract at the OPEN FORUM of the American Association for Respiratory Care 61st International Respiratory Convention and Exhibition, held November 7-10, 2015, in Tampa, Florida.

Supplementary material related to this paper is available at http:// www.rcjournal.com. coughing, and unusual shortness of breath. Exercise and physical training can trigger bronchoconstriction, causing symptoms of EIB in $80-90 \%$ of individuals with asthma. ${ }^{1}$ In addition, $10 \%$ of the population without asthma may experience symptoms related to EIB. ${ }^{2,3}$

\footnotetext{
This work was supported by the University of Kansas Medical Center's School of Health Professions. The authors have disclosed no conflicts of interest.

Correspondence: David M Burnett PhD RRT AE-C, Respiratory Care Education, Mail Stop 1013, University of Kansas Medical Center, 3901 Rainbow Boulevard, Kansas City, KS 66160. E-mail: dburnett@kumc.edu.
}

DOI: $10.4187 /$ respcare. 04553 
Reports have shown that between 30 and $70 \%$ of elitelevel athletes have indicated a prevalence of EIB. ${ }^{3}$ Athletes with a high cardiopulmonary capacity can reach a minute ventilation as high as $200 \mathrm{~L} / \mathrm{min} .{ }^{4}$ As a result of this hyperpnea, it is theorized that the airway epithelium senses water and heat loss, leading to the release of proinflammatory mediators causing bronchoconstriction. ${ }^{5,6}$ Based on previous prevalence data and the effects of highintensity training, a considerable proportion of the 777,263 NCAA athletes ${ }^{7}$ may be predisposed to EIB.

\section{SeE the Related Editorial on Page 994}

Airway remodeling in athletes may occur due to recurring episodes of exercise or training. This airway remodeling may lead to long-term morbidity, including irreversible airway obstruction. ${ }^{8,9}$ Even more notable is the potential for a severe episode of EIB leading to mortality in competitive athletes. Results of a 7-y study by Becker et al ${ }^{10}$ reported 61 EIB-related deaths during competition or practice, with $81 \%$ of these deaths occurring in athletes $<21$ y old.

College athletes' perceived symptoms have not been associated with their results when performing a standardized EIB test. Previous studies on college athletes indicated that self-reporting positive symptoms and history of EIB were not associated with a positive eucapnic voluntary hyperventilation test. ${ }^{11,12}$ Specific to perceived symptoms, Parsons et al ${ }^{12}$ showed that symptoms were not a good predictor of a positive eucapnic voluntary hyperventilation test. Hence, college athletes may discount symptoms of EIB as due to bad conditioning or a poor training day. These findings are consistent with reports suggesting that EIB is frequently underdiagnosed due to lack of awareness among athletes and athletic trainers. ${ }^{13,14}$ The lack of awareness of EIB and subsequent misperception of symptoms may lead to unnecessary morbidity and mortality in college athletes.

An American Thoracic Society clinical practice guideline report on EIB indicated a need for more studies to determine the efficacy of a screening program for EIB on health and performance. ${ }^{6}$ To prepare an effective EIB screening program, we must develop an accurate screening questionnaire that will be useful for stratifying at-risk EIB athletes. The purpose of this study is focused on understanding the perceived impact of EIB in college athletes to help develop a screening questionnaire with the potential to predict an EIB-positive athlete based on a standardized test. This preliminary study will contribute to our all-encompassing work aimed at developing an effective strategy for improving the respiratory health of college athletes and could be implemented on most college campuses. This article discusses the impact that EIB has on college ath-

\section{QUICK LOOK}

\section{Current knowledge}

If untreated, EIB may lead to increased respiratory illness and even death. Previous reports show the prevalence of EIB is high in college student-athletes. However, an athlete's report of EIB symptoms and/or history may not be associated to a positive test.

\section{What this paper contributes to our knowledge}

This study supports the high prevalence rate of EIB in college athletes by self-report. These college athletes tended to acknowledge symptoms of EIB when presented an EIB questionnaire, although they did not report a positive EIB/asthma history. Many athletes are not using an asthma medication, even though they report a past history or current symptoms. College athletes are concerned that EIB/asthma is affecting their sports performance.

letes, including self-reported: (1) history of EIB and/or asthma, (2) symptoms of EIB, (3) medication use, and (4) concern about EIB affecting their performance.

\section{Methods}

Participants in this descriptive study were selected from athletes at the University of Kansas during the 2014-2015 academic year. Athletes were presented a questionnaire with 16 questions relating to respiratory and allergy history, perceived symptoms, and medications (see the supplementary materials at http://www.rcjournal.com). All questions have been previously included in a health survey developed by the United States Olympic Committee. In addition, 6 questions relating to perceived EIB symptoms and athletes' concern about EIB affecting sports performance were presented in the format of a 5-point Likert scale (see the supplementary materials). An answer of $\geq 2$ (some of the time) on the Likert scale was considered as a positive response. The questionnaire was explained by the same head athletic trainer from the sports medicine staff during participating team meetings. All participation was voluntary, and informed consent was obtained from every participant before completion of the questionnaire. The study received approval from the Institutional Review Board at University of Kansas and University of Kansas Medical Center.

\section{Statistical Analysis}

Descriptive statistics were used to describe group characteristics as shown in Table 1. Numbers and proportions 
Table 1. Characteristics and Questionnaire Response Data

\begin{tabular}{lc}
\hline \hline \multicolumn{1}{c}{ Variables } & Values \\
\hline Participants, $n$ & 196 \\
Male sex, \% & 56 \\
Age, mean (range) y & $19.8(18-23)$ \\
History of asthma or EIB, $n(\%)$ & $56 / 196(28.6)$ \\
Symptoms of asthma or EIB, $n(\%)$ & $93 / 196(47.4)$ \\
Reported history of asthma/EIB or symptoms, & $102 / 196(52)$ \\
$\quad n(\%)$ & $46 / 140(32.9)$ \\
No history of EIB but report EIB symptoms, \\
$\quad n(\%)$ \\
Reported history of asthma or EIB but currently \\
$\quad$ not using a respiratory medication, $n(\%)$ \\
Concerned that asthma/EIB may be affecting \\
$\quad$ their sports performance, $n(\%)$
\end{tabular}

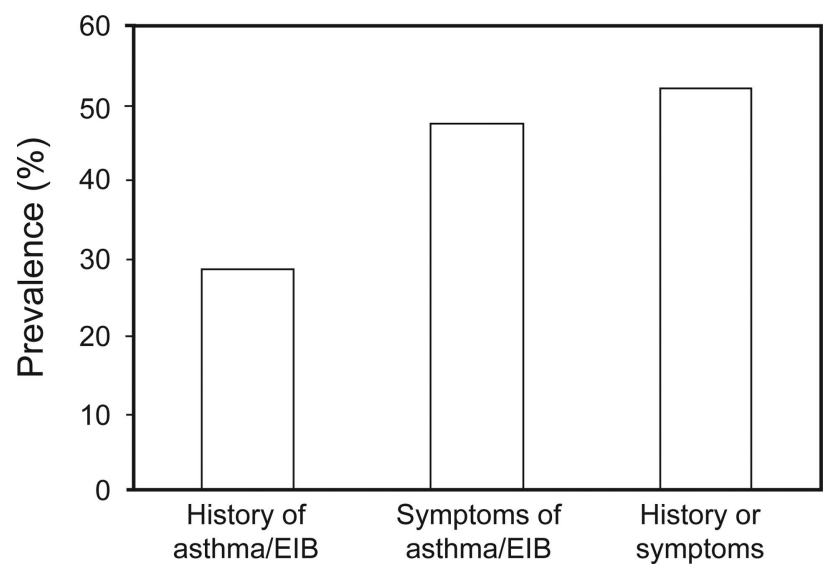

Fig. 1. Proportion of athletes reporting a history and symptoms of asthma or exercise-induced bronchoconstriction (EIB).

were used to explain the prevalence and perception of EIB/asthma in college athletes.

\section{Results}

Two hundred thirty-four athletes completed the questionnaire. Responses were complete from 196 of 234 athletes (84\%). Participant characteristics and questionnaire responses are presented in Table 1. Almost 29\% (56 of 196) of the athletes self-reported a history of EIB or asthma (Fig. 1). Self-reported history of EIB or asthma varied greatly among sports (Fig. 2). Approximately $47 \%$ (93 of 196) of the athletes reported having symptoms of EIB or asthma (questions 6, 7, and 1-4 of the Likert scale), as shown in Figure 1. Over 50\% (102 of 196) of the athletes self-reported a positive history of EIB/asthma or indicated symptoms of EIB (Fig. 1). Interestingly, almost 33\% (46 of 140) indicated symptoms of EIB or asthma, although they did not report a positive history by diagnosis. Twenty-five percent (14 of 56) of athletes self-reporting a history of EIB or asthma did not report the use of a respiratory medication. Last, almost 10\% (19 of 196) of athletes reported concern that asthma or EIB may be affecting their sports performance.

\section{Discussion}

The purpose of this study was to evaluate the prevalence and perceived impact of EIB in college athletes by a selfreport questionnaire administered during routine team meetings. This study demonstrated that we could collect data from a majority (84\%) of questionnaires distributed to athletes on 8 different sports teams. Results of our study indicate that we may improve the burden of EIB in college athletes by: (1) educating athletes, trainers, coaches, and parents about EIB; (2) helping in the development of accurate EIB screening programs, and (3) assuring the proper treatment of EIB-positive athletes to mitigate associated morbidity and mortality.

The result of this study suggests that about $29 \%$ of college athletes report a past history of EIB or asthma. This is on the high end of the range (10-31\%) recorded in past studies, including self-reports on prevalence of EIB in athlete populations. ${ }^{11,12,15,16}$ In addition, $47 \%$ of the athletes in this study perceived symptoms of EIB. These data raise concern that some athletes may not be appropriately screened and may potentially be experiencing silent episodes of EIB, resulting in possible long-term respiratory health complications and a potential fatal event.

Many athletes may fail to report symptoms suggestive of EIB and do not seek medical care to undergo a formal diagnosis. This may be attributed to athletes' lack of awareness of symptoms and their association with EIB. Rather than recognizing the potential of having EIB, athletes may consider their symptoms to be indicative of poor conditioning or a bad training day. As a result, athletes may continue to experience silent episodes of EIB. A previous study demonstrated that only $14 \%$ (6 of 42 ) of the college athletes who tested positive for EIB reported a prior history of EIB or asthma. ${ }^{12}$ However, 36\% (15 of 42) of those same athletes who were found to be EIB-positive reported symptoms when presented a questionnaire on EIB. Similarly, our findings support the theory that athletes may not seek medical attention when symptoms occur, since 33\% of the athletes reporting symptoms of EIB in our study did not report a positive history of asthma or EIB. This supports the idea that athletes may attribute EIB symptoms to a cause other than respiratory issues. These findings suggest that specialists in respiratory care need to do a better job at teaching awareness of EIB to athletes, coaches, trainers, and parents. As previously mentioned, this can be 


\section{Exercise-Induced Bronchoconstriction in College Athletes}

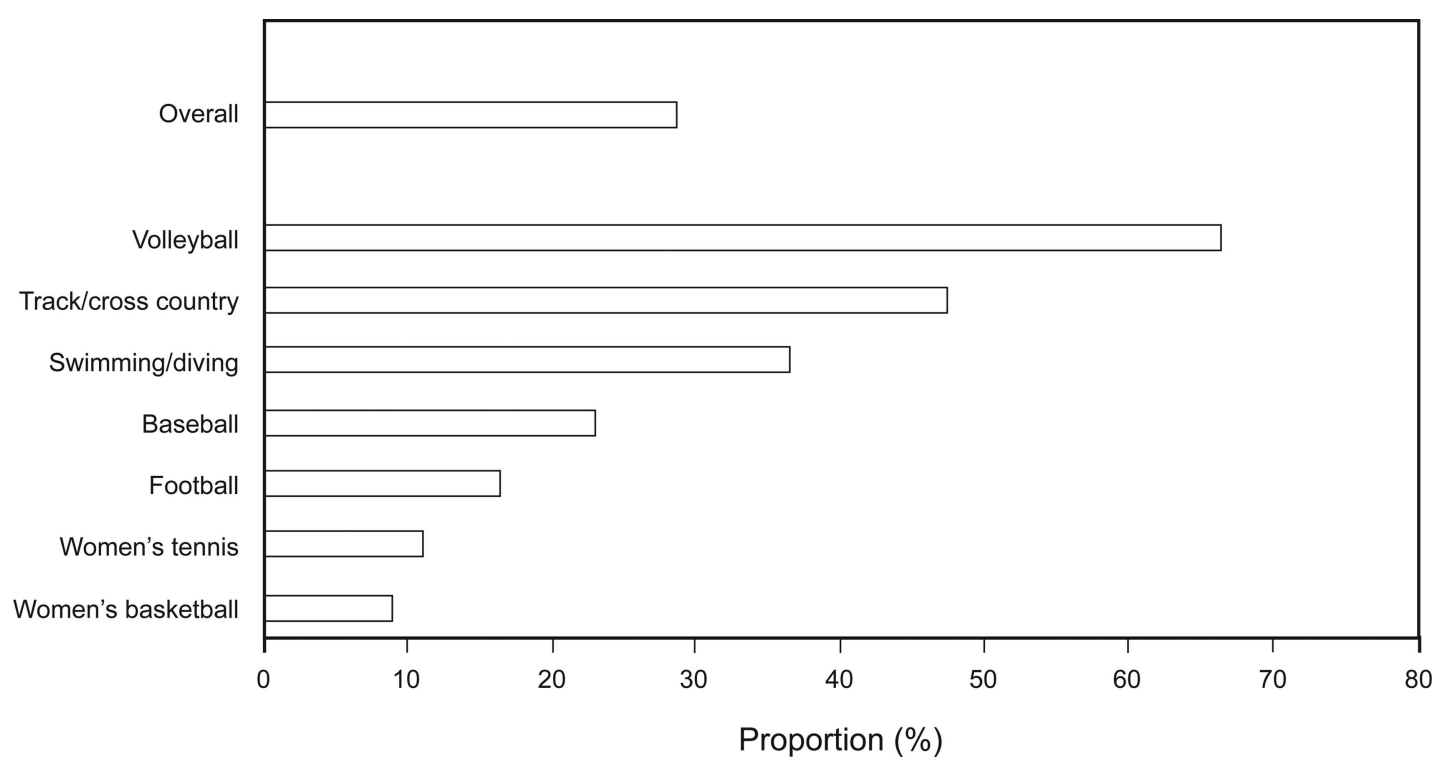

Fig. 2. Prevalence of exercise-induced bronchoconstriction among college athletes, by sport. Softball not reported due to small number reported $(n=2)$.

critically relevant, since a vast majority (81\%) of EIB deaths were in the college athlete age group or younger. ${ }^{10}$

Evidence-based guidelines recommend the prophylactic use of a short-acting bronchodilator ( $\beta_{2}$ agonists) shortly before exercise as the main therapeutic treatment for EIB, ${ }^{17}$ when warm-up prior to intense activity does not permit a refractory period. Another practice for reducing the need to rely on pharmacologic treatment is the athletes' awareness of environmental triggers, including cold dry air, pool and turf chemicals, and poor air quality days. When pharmacologic treatment is necessary, the National Athletic Trainers Association guidelines suggest that athletic trainers in direct contact with athletes should understand the use, misuse, and abuse of $\beta_{2}$ agonists. ${ }^{13}$ A previous study showed that tachaphylaxis was associated with a $\beta$ adrenergic drug when treating bronchoconstriction in EIB subjects. ${ }^{18}$ Although guidelines support the use of $\beta_{2}$ agonists to minimize or prevent symptoms of asthma, asthma patients may not adhere to their prescribed medication treatment. ${ }^{19}$ Our study revealed that $25 \%$ (14 of 56) of the athletes who indicated a history of asthma or EIB did not report taking any asthma medication. More work is needed to educate the sports community and determine the barriers for the adverse effects, abuse, and non-use of asthma medications in athletes.

EIB can reduce participation in sports and may have a negative effect on an athlete's quality of life. Valued life activities, including participation in sports, have been reported to be negatively impacted by asthma and associated with asthma-specific quality of life. ${ }^{20}$ Our findings showed that almost $10 \%$ (19 of 196) of the athletes reported concern that asthma may be affecting their sports performance.
It is possible that EIB symptoms may be affecting the college athletes' quality of life, but more qualitative work is needed to investigate such a relationship. Furthermore, it is unknown whether sports performance will improve after an EIB athlete is accurately diagnosed and properly treated.

Some athletes may continue to present with EIB symptoms although they test negative during an adequate exercise challenge test. As a result, it has been suggested that a second EIB challenge is necessary to improve the sensitivity of the challenge test. ${ }^{21}$ Also, consideration of a differential diagnosis should be made when an athlete continues to present with symptoms of EIB after testing negative. Symptoms that may mimic EIB include vocal cord dysfunction, overtraining syndrome, right to left shunt, and even hyperventilation syndrome. ${ }^{22}$

The present study has some limitations. The prevalence data collected is from self-reported questionnaires while we prepared to perform standardized EIB testing on the same athletes. This study used a convenience sample of athletes from a single university. We did not test athletes from all sports, so our data may not be representative of athletes on all teams. Larger studies are needed to provide a better generalization of the college athletic population and investigate any differences between sports.

\section{Conclusions}

Our data revealed that a majority of the questionnaires were returned and completed by the college athletes. In addition, the Departments of Pulmonary Critical Care Medicine and Respiratory Care Education received support from 
the sports medicine team and coaches for conducting our study with the athletes. Based on responses to our questionnaire, it is common for college athletes to report a history of EIB or asthma. Almost half of all college athletes perceived having symptoms of EIB when provided a questionnaire. Also, a good proportion of the college athletes did not report any use of a respiratory medication although they indicated a history of EIB or asthma. Our study suggests that college athletes are concerned that asthma or EIB may be affecting their sports performance. Findings from this study indicate that we can improve EIB awareness and education through collaboration with sports medicine staff, athletes, and parents. Future studies are needed to determine the clinical importance of an EIB screening program and concurrent development of a validated screening tool for athletes while comparing qualitative and quantitative data from a questionnaire with the results from a standardized EIB test that can be performed on most college campuses. It is imperative that we develop an accurate screening tool to correctly diagnose and treat athletes who are EIB-positive.

\section{ACKNOWLEDGMENTS}

We thank the subjects who participated in this study. Also, we appreciate the sports medicine team and coaches for allowing us to work with the athletes.

\section{REFERENCES}

1. McFadden ER, Jr., Gilbert IA. Exercise-induced asthma. N Engl J Med 1994;330(19):1362-1367.

2. Gotshall RW. Exercise-induced bronchoconstriction. Drugs 2002; 62(12):1725-1739.

3. Weiler JM, Bonini S, Coifman R, Craig T, Delgado L, Capão-Filipe $\mathrm{M}$, et al. American Academy of Allergy, Asthma and Immunology Work Group report: exercise-induced asthma. J Allergy Clin Immunol 2007;119(6):1349-1358.

4. Dempsey J, Hanson P, Pegelow D, Claremont A, Rankin J. Limitations to exercise capacity and endurance: pulmonary system. Can J Appl Sport Sci 1982;7(1):4-13.

5. Hallstrand TS, Moody MW, Wurfel MM, Schwartz LB, Henderson WR Jr, Aitken ML. Inflammatory basis of exercise-induced bronchoconstriction. Am J Respir Crit Care Med 2005;172(6):679-686.

6. Parsons JP, Hallstrand TS, Mastronarde JG, Kaminsky DA, Rundell $\mathrm{KW}$, Hull JH, et al. An official American Thoracic Society clinical practice guideline: exercise-induced bronchoconstriction. Am J Respir Crit Care Med 2013;187(9):1016-1027.

7. Athlete Membership of the NCAA. http://www.ncaa.org/about/ who-we-are/membership/composition-and-sport-sponsorship-ncaamembership. Accessed November 30, 2015.
8. Bousquet J, Jeffery PK, Busse WW, Johnson M, Vignola AM. Asthma: from bronchoconstriction to airways inflammation and remodeling. Am J Respir Crit Care Med 2000;161(5):1720-1745.

9. Tiddens H, Silverman M, Bush A. The role of inflammation in airway disease: remodeling. Am J Respir Crit Care Med 2000;162(2 Pt 2):S7-S10.

10. Becker JM, Rogers J, Rossini G, Mirchandani H, D’Alonzo GE Jr. Asthma deaths during sports: report of a 7-year experience. J Allergy Clin Immunol 2004;113(2):264-267.

11. Parsons JP, Cosmar D, Phillips G, Kaeding C, Best TM, Mastronarde JG. Screening for exercise-induced bronchoconstriction in college athletes. J Asthma 2012;49(2):153-157.

12. Parsons JP, Kaeding C, Phillips G, Jarjoura D, Wadley G, Mastronarde JG. Prevalence of exercise-induced bronchospasm in a cohort of varsity college athletes. Med Sci Sports Exerc 2007;39(9):14871492.

13. Miller MG, Weiler JM, Baker R, Collins J, D’Alonzo G. National Athletic Trainers' Association position statement: management of asthma in athletes. J Athl Train 2005;40(3):224-245.

14. Weiler JM, Hallstrand TS, Parsons JP, Randolph C, Silvers WS, Storms WW, Bronstone A. Improving screening and diagnosis of exercise-induced bronchoconstriction: a call to action. J Allergy Clin Immunol Pract 2014;2(3):275-280.e7.

15. Randolph CC, Dreyfus D, Rundell KW, Bangladore D, Fraser B. Prevalence of allergy and asthma symptoms in recreational roadrunners. Med Sci Sports Exerc 2006;38(12):2053-2057.

16. Weiler JM, Ryan EJ 3rd. Asthma in United States Olympic athletes who participated in the 1998 Olympic winter games. J Allergy Clin Immunol 2000;106(2):267-271.

17. National Asthma Education and Prevention Program. Expert panel report 3 (EPR-3): guidelines for the diagnosis and management of asthma-summary report 2007. J Allergy Clin Immunol 2007;120(5 Suppl):S94-S138

18. García R, Guerra P, Feo F, Galindo PA, Gómez E, Borja J, Fernandez-Pacheco R. Tachyphylaxis following regular use of formoterol in exercise-induced bronchospasm. J Investig Allergol Clin Immunol 2001;11(3):176-182.

19. Spector SL, Kinsman R, Mawhinney H, Siegel SC, Rachelefsky GS, Katz RM, Rohr AS. Compliance of patients with asthma with an experimental aerosolized medication: implications for controlled clinical trials. J Allergy Clin Immunol 1986;77(1 Pt 1):65-70.

20. Katz PP, Yelin EH, Eisner MD, Earnest G, Blanc PD. Performance of valued life activities reflected asthma-specific quality of life more than general physical function. J Clin Epidemiol 2004;57(3):259267.

21. Anderson SD, Pearlman DS, Rundell KW, Perry CP, Boushey H, Sorkness CA, et al. Reproducibility of the airway response to an exercise protocol standardized for intensity, duration, and inspired air conditions, in subjects with symptoms suggestive of asthma. Respir Res 2010;11:120.

22. Boulet LP, O'Byrne PM. Asthma and exercise-induced bronchoconstriction in athletes. N Engl J Med 2015;372(7):641-648.

This article is approved for Continuing Respiratory Care Education credit. For information and to obtain your CRCE

(free to AARC members) visit

www.rcjournal.com

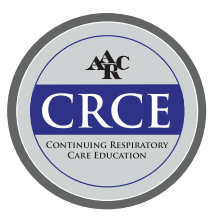

